\title{
Systems Dynamics and Serious Video Games in an Appropriation Strategy of a Decision Support System for Small Livestock Farmers
}

\author{
https://doi.org/10.3991/ijim.v14i15.14597 \\ Urbano Eliécer Gómez Prada $(\bowtie)$ \\ Bolivarian Pontifical University, Bucaramanga, Colombia \\ University of the Balearic Islands, Palma, España \\ urbano.gomez@upb.edu.co \\ Martha Lucía Orellana Hernández \\ Autonomous University of Bucaramanga, Bucaramanga, Colombia \\ Jesús María Salinas Ibáñez \\ University of the Balearic Islands, Palma. España
}

\begin{abstract}
This document presents a Decision Support System (DSS) aimed at small livestock farmers who have not made use of Information Technologies (IT) in their production systems. The DSS was built based on the finite difference equations of a simulation model in System Dynamics in whose definition the beneficiaries participated and served as a base for the development of a serious video game. The DSS and the Serious video game is supported in a Web and Mobile Architecture. The simulation model and the serious video game are used as support tools in the training given to users to learn how to use the DSS. These three tools are the result of a doctoral research project, which used two methodologies during its execution: Design and Development Research and the Case Studies methodology. The tools were applied in an appropriation strategy with livestock farmers of the department of Santander in Colombia, where resistance to change and cultural attachment causes a low adoption of technology. The inclusion of gamification elements helps the user to understand the connection of these elements and their processes in a real farm, know the large volume of data managed by the DSS, enhance the process by making it more fun, improve the learning curve and provide useful data for tracking the use of the DSS. 16 months after the end of the training, the DSS has more than 13000 reported records about the activities of the farmers in their farms.
\end{abstract}

Keywords - Information Technologies; appropriation; information systems; decision-making; bovine production system; system dynamics; serious video game. 


\section{Introduction}

The livestock farmers of the Colombian rural sector need ways to improve the decisions they make concerning their production processes to mitigate the losses of data and the uncertainty of the result of their choices [1]. This document presents three tools aimed at mitigating this need: A Decision support system (DSS), a simulation model and a Serious video game.

The three tools presented in this article are aimed at small livestock farmers. The livestock farmers for whom this DSS is designed to have a Bovine Production System with a maximum of 25 animals and an income of less than 60 legal minimum monthly wages per year [2]. Many of these livestock farmers have low Information Technologies (IT) adoption. This generates errors or delays in decision-making, unawareness of losses and a lack of profits [3]. Because of this, rural development must be supported by better information [4] and accelerating the appropriation of the DSS [5] with adoption of strategies [6].

The interest to work in the development of a DSS which is based on a simulation model that integrates with a Serious video game was inspired by the need of tools that deliver useful information for agricultural practices, and by the training needed so producers would modify their behavioural patterns [7].

The small livestock farmers participated in the development of the tools to suggest features that the DSS must have, such as the efficiency of professional performance and the possibility of evolution in training, and to help in understanding the volumes of information that occur with the processes.

The integration of the three elements seeks to improve the adoption of IT by taking the advantages offered by the simulation model. The serious video game to facilitate the understanding of the productive system and the benefits for decision-making between different alternatives that must be analyzed based on the objective pursued in the managed system as described [8].

For the development of the DSS, the social context was considered to identify the cognitive strategies that the system must have, an important guideline in the rural sector as stated by [9]. The information regarding the processes was obtained directly from the livestock farmers. Such information was then represented in the three tools: simulation model, serious video game, and DSS. The mechanics of the serious video game and the diagnosis reports from the DSS were based on the equations by finite differences from the simulation model.

\section{Frame of Reference}

A systematic review showing the degree of progress of IT Appropriation in agribusiness and the need to contribute to that appropriation was presented in [3]. The review was carried out in Scopus and Web of Science and sought to know the degree of use of modelling with systems dynamics and serious video games in strategies for appropriating DSS for agro-industrial producers. As a result, it was concluded that, although there are works in this regard, the opportunities to unify knowledge and to align in the three 
IT tools are presented, the way of carrying out the processes to plan the productive strategies taking advantage, in simulation tools, benefits they offer such as support for understanding, comparing scenarios and raising awareness about the volume of data generated in production processes.

The frame of reference that supports the DSS is composed of topics such as Bovine Production Systems, IT Appropriation, Gamification and Serious video game. A summary of each of the topics that support the DSS is presented below.

\subsection{Decision Support System (DSS)}

DSS are information systems that, in addition to being a set of various components oriented towards the management of data and information organized for use, offer decision alternatives to various problems [10]. They are also defined as computer systems that help make decisions using data and models for unstructured problems [11].

In the decision-making process, a fundamental aspect is the understanding of the processes, since this is taken in stages such as the analysis of the information and the evaluation of alternative solutions according to the evaluation of the possible results [12]. Decisions can be supported in simulation and strengthen training activities with experiments [13].

\subsection{IT appropriation}

The IT Appropriation, according to [14] is the ability or competence to use tools that manage information to generate changes in the way processes are performed, increasing the quality of products and improving results.

The proposal in which the DSS is framed seeks the appropriation of the producers supporting the education, competitiveness, and collaboration provided by the simulation model and the Serious video game.

\subsection{Bovine production systems}

A Bovine Production Systems is an organization of elements normally called a farm. It consists of dynamic economic activity that includes the production and commerce of bovine agricultural products which has demographic, biophysical, productive and financial aspects that must be controlled to generate profits, as stated in [15].

\subsection{Gamification and serious video games}

Gamification incorporates game strategies to support the improvement of skills and to internalize knowledge in a more fun way, developing commitment and encouraging the spirit of improvement thanks to the motivation it achieves from the learners [16].

Serious video games are interactive digital instruments that, through controls, simulate experiences in an electronic device. A Serious video game is a video game that is 
designed with an educational purpose beyond pure fun (i.e. it is aimed at both entertainment and learning) [17].

Serious video games contemplate aspects to generate knowledge, that is, they give the player the possibility to control different variables, make decisions and generate experiences for education, and incentivize competitiveness by generating patterns that lead to deduce information and modify strategies based on these experiences [18].

\section{Research Methodology}

The frame study is aimed at an Appropriation strategy of IT in which the development of three tools is one of its objectives. The Appropriation strategy was supported by Design and Development Research and the Case Study methodology, the simulation models are supported in System Dynamics and the development of the DSS and Serious video game was supported by RUP.

Design and Development is recommended when it is necessary to improve practice by applying ICT tools and processes that fit the context, where the beneficiaries participate in the formulation, execution, and reflection [19] and guide the exploration of new context-based learning environments [20]

Case Study is given by the importance of working with communities, each assumed as a single social instance for the analysis, by working with each participant, it facilitates decision-making due to the ability to generate hypotheses and discoveries [21].

System Dynamics is a methodology to learn, explain and recreate phenomena in terms of simulation models that allows the observation of the behaviour of a system under different circumstances [22]. The models are based on causal loop diagrams and one of them, the Flow-Level diagram, represents integral equations in non-linear finite differences that allow simulating strategies or scenarios in the system [23].

RUP is a software development methodology that identifies four phases for the generation of technical documents and the software product [11]. The products are carried out in workflows, and their execution must follow good practices like making correct use of version control. RUP is considered an iterative and incremental methodology. Iterative, because it allows repeating the cycle of the four phases in more than one opportunity, and incremental, because in each iteration the scope is increased.

An example was carried out during the development of the DSS; it is presented in Table 1. Such a table shows the phases and their purposes, as well as the products obtained (the products that make the DSS were improved in three iterations). 
Table 1. Phases and products in the construction of the DSS according to RUP

\begin{tabular}{|l|l|}
\hline \multicolumn{1}{|c|}{ Phase: Purpose } & \multicolumn{1}{|c|}{ Products } \\
\hline $\begin{array}{l}\text { Start: Definition of entities and processes structure in } \\
\text { a productive system }\end{array}$ & $\begin{array}{l}\text { Description of the processes of the Bovine Produc- } \\
\text { tion Systems } \\
\text { Description of the simulation model with System } \\
\text { Dynamics } \\
\text { Description of the serious video game } \\
\text { List of Requirements }\end{array}$ \\
\hline $\begin{array}{l}\text { Elaboration: Establishment of architectural frame- } \\
\text { work, plan, specific models such as any of UML }\end{array}$ & $\begin{array}{l}\text { Design Document } \\
\text { Architecture } \\
\text { Use case diagram* } \\
\text { Activity diagrams* } \\
\text { Entity-relationship } \\
\text { User views* }\end{array}$ \\
\hline Construction: Programming & $\begin{array}{l}\text { A simulation model with System Dynamics } \\
\text { Serious video game } \\
\text { DSS }\end{array}$ \\
\hline Transition: Use in a real environment & DSS Acceptance Tests \\
\hline
\end{tabular}

* In which the livestock farmers participated.

\section{Results}

In research was proposed the Appropriation strategy which was applied, improved and validated in several sessions with livestock farmers of the Santander, Colombia in the municipalities of Betulia, Valle de San José and Lebrija. The strategy has ten phases:

1) Formalization of knowledge and elaboration of the frame of reference

2) Construction of the IT tools

3) Characterization of livestock farmers and their Bovine Production Systems

4) Formalization of the simulation model

5) Updating and validation of tools

6) Training with the serious video game

7) Training of the DSS for the management of the simulated farm

8) Use of DSS with help for the management of the real farm

9) Use of DSS without help for the management of the real farm

10) Measurement of the tools use

In these phases are defined three moments in which the tools are used and from which the total objective of appropriation emerges is given by the livestock farmer receives an induction on simulation model with System Dynamics with simple models so that they know the methodology of the System Dynamics and support with their ideas the construction of a new version of the model for the Bovine Production Systems Because when the developer finishes the new version of the Serious video game, which are presented in several sessions and this aids them to know the structure and learn that the decisions taken can be consulted on the DSS.

The serious video game and the DSS follows three moments presented in Figure 1, the description of each moment is as follows: 
1) The livestock farmer interacts with the serious video game in a simulated production system and then reviews the result reports. By taking advantage of that possibility of verifying the results in the DSS of the games, the farmer can reflect on his decisions so he can achieve a better result in the next playing experience. The exercise seeks for the livestock farmer to become aware of the volume of data he handles in his Bovine Production Systems. In this exercise, the livestock farmer has the aid of a tutor (in this case the researcher), who supports him in the management of the Serious video game. To raise awareness about the benefits of having access to the information generated by the DSS, the tutor asks the farmer questions about the system, which is then resolved by the reports generated by the DSS. After the training, the farmer can play again to further improve his knowledge about the system.

2) After the simulation exercises with the video game, which allows the understanding of the purpose and information generated by the DSS, the livestock farmer interacts directly with the DSS to manage the data of his farm, that is, his real production system. The management of the DSS and its reports allows the livestock farmer to enhance his understanding and decision-making about his farm. In this exercise, the livestock farmer also has the support of a tutor who aids him in the management of the DSS.

3) The livestock farmer continues to interact directly with the DSS as a support tool for the management and decision-making of his real farm or productive system, but he begins to do so autonomously, that is, without the tutor's aid.

Next, the simulation model, the Serious video game and the DSS are presented, as well as the integrated way in which they were built, describing the contributions that the SM and the Serious video game make to the DSS.
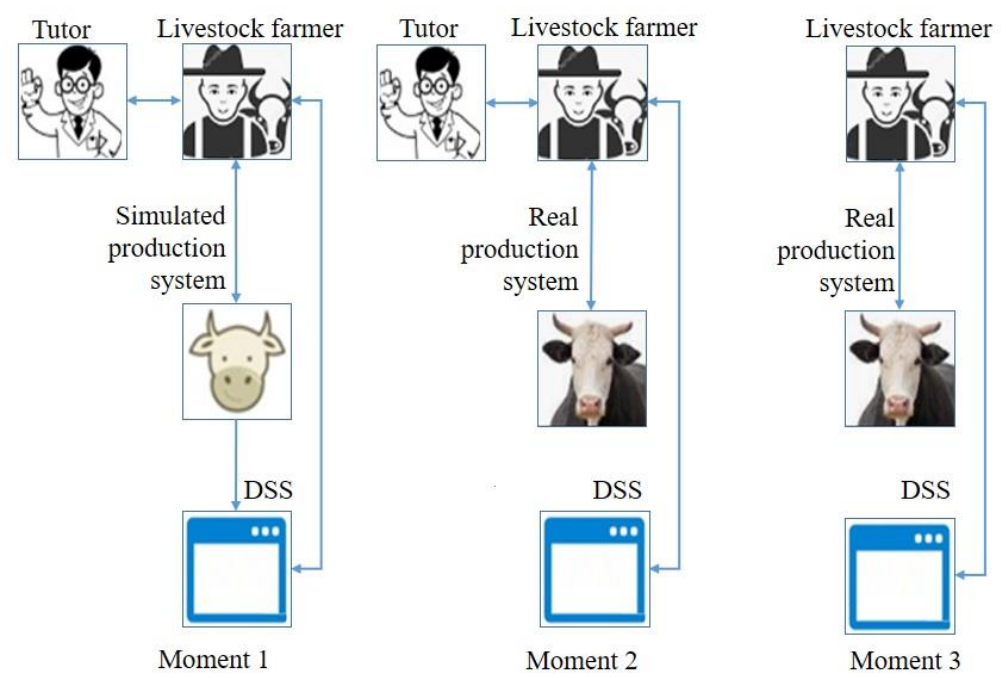

Fig. 1. Moments of the appropriation strategy 
The tools that were developed to accompany these sessions in the appropriation strategy are described below.

\subsection{Simulation model}

The simulation model represents the Bovine Production Systems. It defines the processes and elements of the system to contemplate in the appropriation strategy. It was developed with the participation of livestock farmers in the first sessions held with them and subsequently implemented in System Dynamics.

Figure 2 presents the general influence diagram of a Bovine Production Systems, where feedback cycles that occur in the system can be seen. For example, starting from the variable "animal", it can be seen that when hydrating and feeding, the animals grow by generating greater weight that can be sold to generate income to increase capital, which in turn allows the purchasing of more animals.

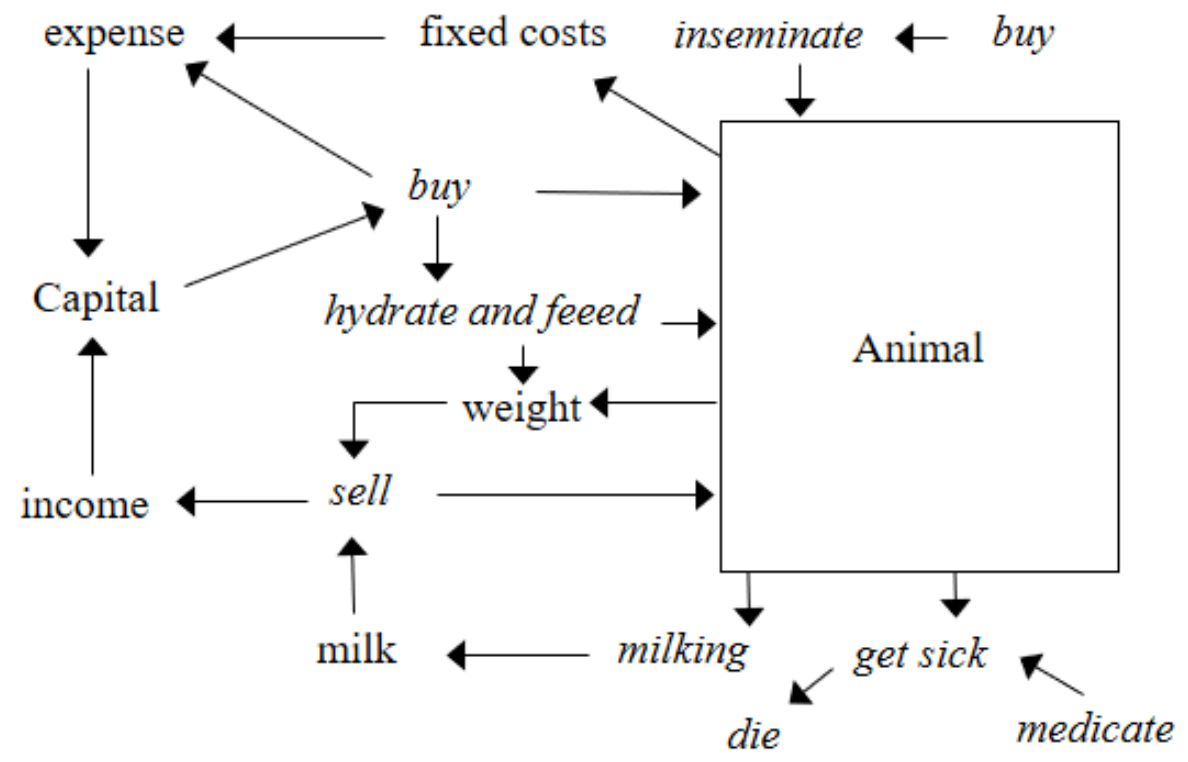

Fig. 2. General influence diagram of a Bovine Production Systems

Figure 3 shows a part of the age groups of the "Animal" variable in the influence diagram: Veal, Empty cow, Pregnant cow, Cow on rest days, Empty lactating cow and Lactating pregnant cow. 


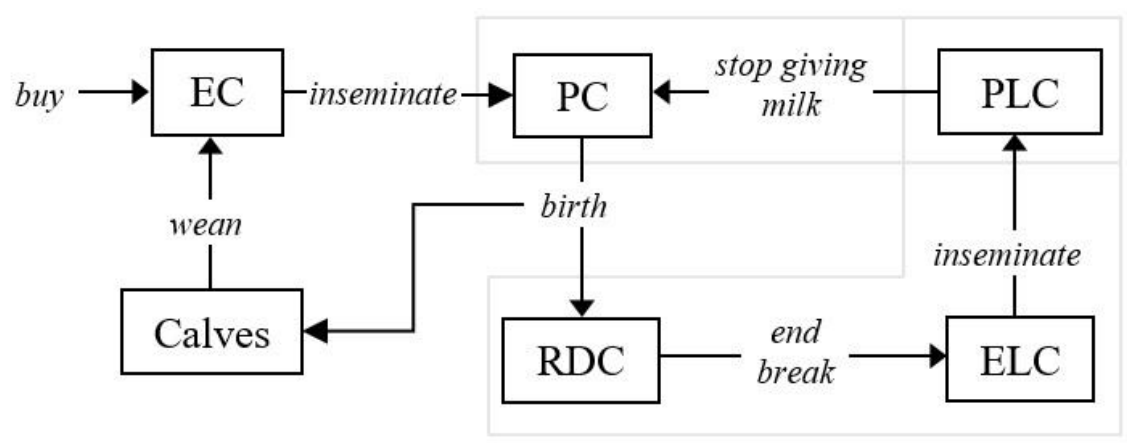

Fig. 3. Influences diagram of the age groups of a Bovine Production Systems

Figure 4 shows the correspondence of those age groups with the Flow-Level diagram of the System Dynamics. From that diagram, equations are obtained by finite differences for the mechanics of the Serious video game and the forecasts of the DSS (Only the parts regarding age groups are presented in the Figures). Additionally, the diagram in Figure 4 shows that the levels correspond to the age groups and the flows correspond to the events (buy, inseminate, give birth, end the rest, inseminate, prepare). An explanation of the diagram is the following:

The process begins by buying an Empty Cow (EC), which is inseminated to become a Pregnant Cow (PC). When the Pregnant Cow (PC) gives birth, it produces a Veal and changes its status to Cow on Rest Days (RDC). After the resting days, the cow changes its status into Empty Lactating Cow (ELC), when it is inseminated again to become a Pregnant Lactating Cow (PLC). Three months before giving birth, the cow stops being milked, and it becomes a Pregnant Cow (PC) again. The cycle can be repeated for up to 15 deliveries depending on the conditions of the animal. After the Veal finishes its growth process, it is sold or it becomes an Empty Cow (EC) that can become inseminated, and the cycle starts again.

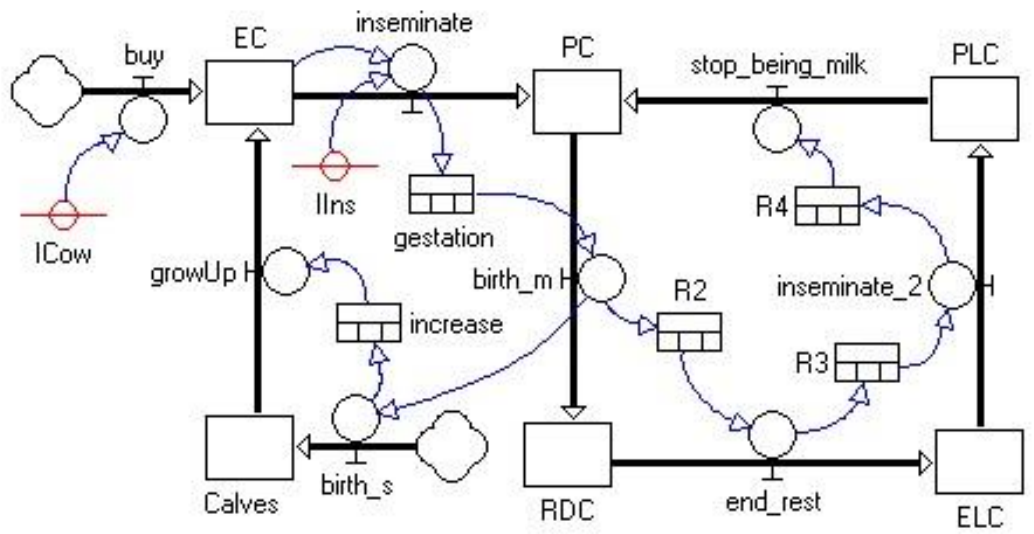

Fig. 4. Flow-Level diagram of the age groups of a Bovine Production Systems 
Below are presented, as examples, three equations corresponding to the flow-level diagram for the level EC and the events "buy" and "inseminate" (events in which the livestock farmers decide in the video game and the real farm, "ICow" and "IIns" are the variables to identify in the model that an animal was purchased or inseminated). These equations along with 58 others are iterated over time and generate the results in each game played on the serious video game.

$$
\begin{gathered}
\text { buy }_{t}=\text { ICow } \\
E C_{t}=E C_{t-1}+\text { buy }_{t}+\text { growUp }_{t}-\text { inseminate }_{t} \\
\text { inseminate }_{t}=\text { if }\left(E C_{t-1}>\text { IIns, IIns }, 0\right)^{\text {ins }}
\end{gathered}
$$

\subsection{Serious video game}

The serious video games incorporate gamification to familiarize the player with the use of IT, showing consistency with the model, simulating the production processes they already know and it is mainly used in training sessions so the livestock farmers can make decisions on the Bovine Production Systems simulated and make them aware of the volume of information that is given in a farm since the results can be consulted in the DSS. It was developed using Unity, a development engine for the creation of interactive experiences and games [24], also following the same RUP methodology used while creating the DSS and it simulates the administration of a farm, given that its mechanics follow the simulation model and it is.

Figure 5 presents part of the class diagram of the Serious video game, where it can be seen that a game (that is, a Bovine Production System) is made up of lots that in turn are made up of animals, the same events can be seen in the diagram.

The Serious video game followed the guidelines expressed in the model, but with a user-friendly interface that simulates the administration of a farm. Every decision that the livestock farmer makes and every event that happens in the game is saved as a backup in an XML file whose name corresponds to a unique identifier with a header that is then sent to the DSS.

The Serious video game generates a report for every decision or event that occurs in a game. The livestock farmer can then view the information in the DSS as if it corresponded to a real farm, and then answer questions about his decisions to review his mistakes and successes during the game. 


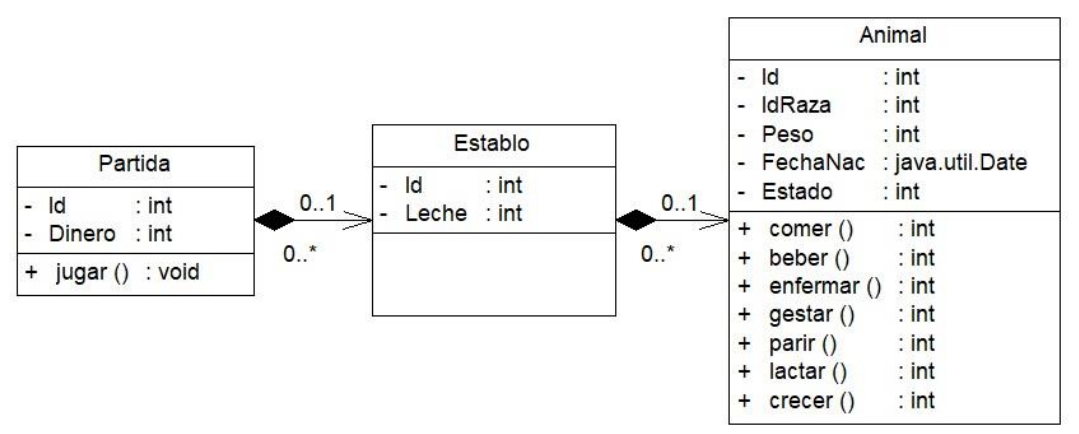

Fig. 5. Part of the Class diagram of the Serious video game

It is expected that by allowing the livestock farmer to review all the decisions taken during the game, the learning process for using the DSS is made easier, and the importance of using this knowledge in a real system is made clear.

At the beginning of a game, the player receives a farm with an empty table, as well as information about the parameters of the game, such as the initial amount of money the player has. At the top, the player can see the controls for the decisions he can make.

An example of the Serious video game is presented in the heading of Figure 6, where two animals are being administered. In the upper part, you can see the controls offered by the Serious video game and on the right, the money of the game and the data of the selected animal.

The gameplay of the Serious video game is presented in Figure 6, where two animals are being handled. The upper bar shows the controls offered by the Serious video game, and the right panel shows the money the player has and the average data of the selected animals. When the livestock farmer starts to have a better performance in the simulation, the tutor provides a code for a new game so that the player gets to face more complex scenarios, such as a greater probability of disease in animals, different animal purchasing prices, among others.

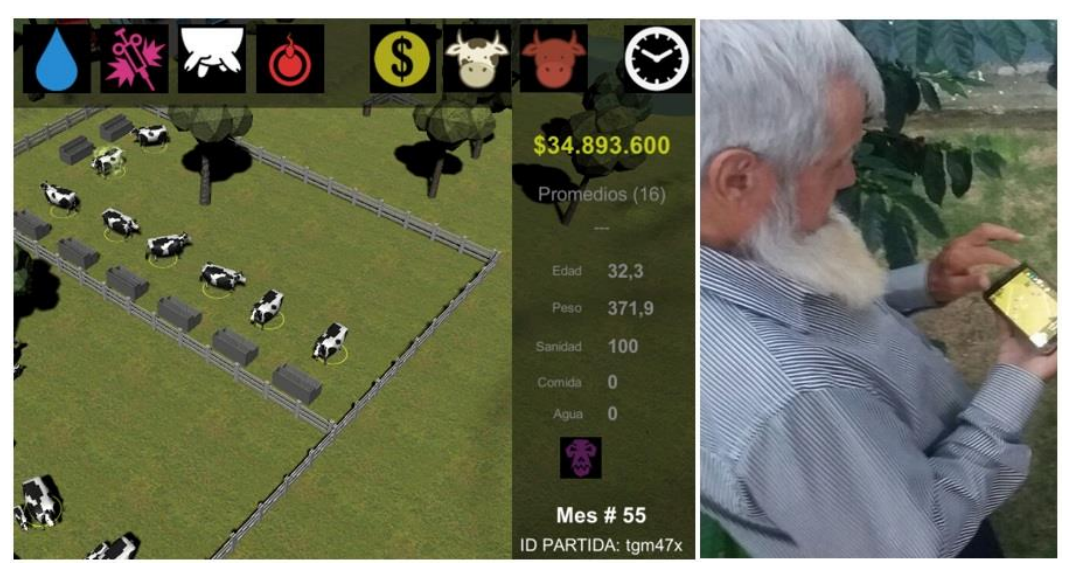

Fig. 6. Example of a game in the Serious video game 


\subsection{Decision Support System (DSS)}

The Decision support system (DSS) is hosted in a server that can be accessed by the trainees. It was developed in HTML5, PHP and JavaScript for Web, Java for mobile, and it has a database in MySQL and SQLite, respectively.

Figure 7 presents part of the entity-relationship diagram of the DSS. It can be seen that each animal has a breed assigned, and also a record of events. The figure shows that the elements and events of the SM are the same that those in the Serious video game presented in the Serious video game class diagram (Figure 5), those in the game (Figure 6) and those in the DB.

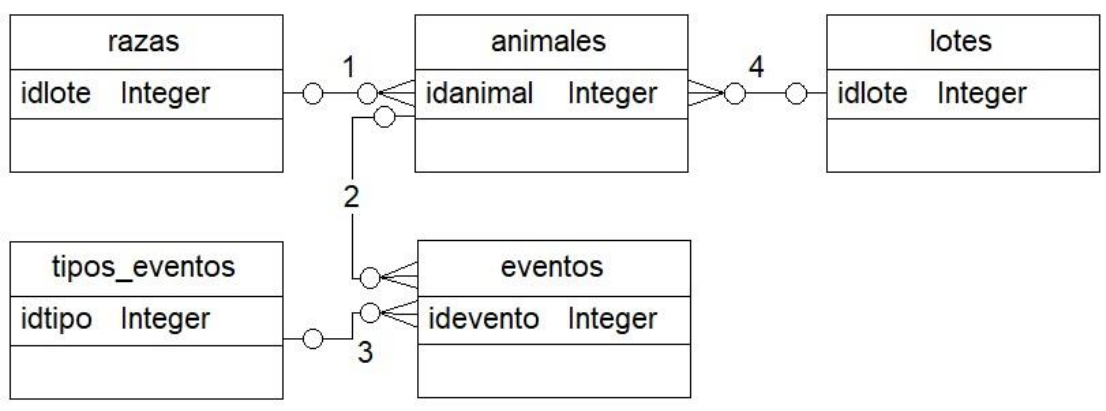

Fig. 7. Part of the database of the DSS

To enable the review of decisions of each game, the DSS receives data from the Serious video game. This allows users to review the decisions that were made in each game in the same way as it would be done with a real production system.

Additionally, these events are shown in the "Events" module, which offers the option of recording each situation that happens to an animal.

The tools were developed following the same structure of the SM to facilitate the development process and the use of the tools in the sessions with the livestock farmers for the management of the Bovine Production Systems. As stated before, the DSS and the Serious video game are integrated, as the DSS shows whatever happened in a play through the Serious video game. An explanation of this is given below.

Figure 8 resembles the architecture diagram and the collaboration diagram of UML. It shows the elements present in the migration, that is, the Serious video game, the web browser and the server (composed of the controller, the model and the view). From that figure, the following features will be presented: the querying process of the DSS, the process of receiving data from the Serious video game, the DSS functionalities and the generation of reports.

Description of the consultation process: After the migration of the data of the game, the livestock farmer can log in to see details of the product information of animals, which are shown in graphic reports. The description of the querying process is presented in figure 9 with Arabic numbers: 
1) The Browser makes query through https

2) The Controller receives it

3) The Controller requests information from the Model

4) The Model makes the required queries and delivers the data to the controller

5) The Controller supplies the data to the View

6) The View delivers the result in the browser

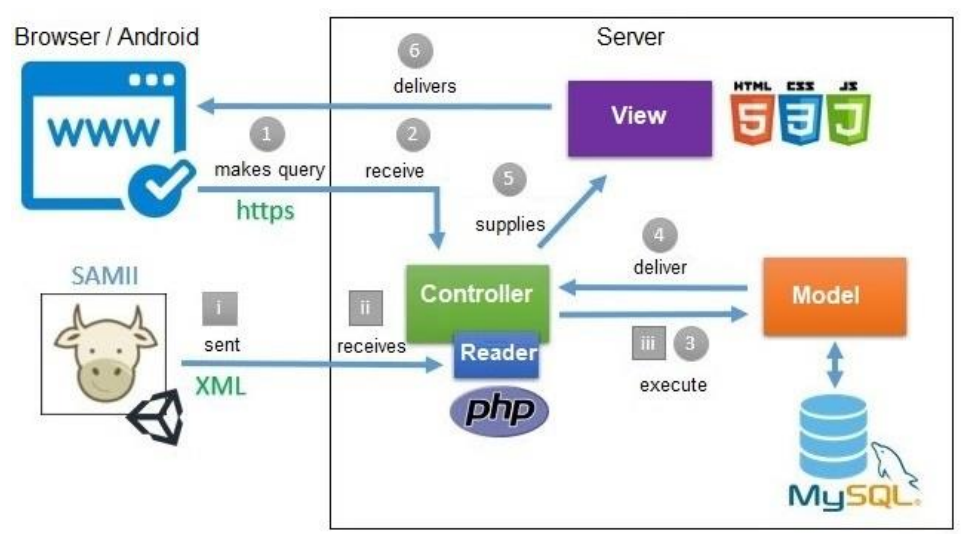

Fig. 8. DSS architecture diagram and DSS collaboration diagram

The reports in the DSS to check productivity are:

1) Age Distribution: Presents a cake diagram with percentages of demographics.

2) Production by Animal: Shows the behaviour curves of each animal according to their age, by event or for a range of dates.

3) Consolidated Production: Presents the total daily milk (total produced, in litres) or weight production (total weight of animals, in kilograms) for a range of dates.

4) Quantity of Records per day: Shows the amount of data entered in the tool per event or for a range of dates (for items with more than 5000 records).

Reception process of the serious video game: As stated before, the serious video game sends data to the DSS, so livestock farmers can log in to see their results and their progress in the use of Serious video game. The description of the migration is presented in figure 9 with roman numerals:

i. The Serious video game generates an XML file that is sent by https to the server.

ii. The Controller receives the data and transforms it into scripts according to the DB.

iii. The Controller runs the scripts to save them at the DB.

iv. An example of data migration from serious video game to DSS is presented below: 
In the Serious video game, the player is initially presented with a table with empty feeders, and to the right, the characteristics of the productive system are shown. In Figure 9, on the right, the game with ID vwfep6 is shown. In that scenario, the game is in month \#1 and the player had bought a cow (which was assigned ID \#656177). The cow was inseminated, and therefore is pregnant. It currently weighed $260 \mathrm{~kg}$. That day, it was supplied with $20 \mathrm{~kg}$ of grass and 26 liters of water.
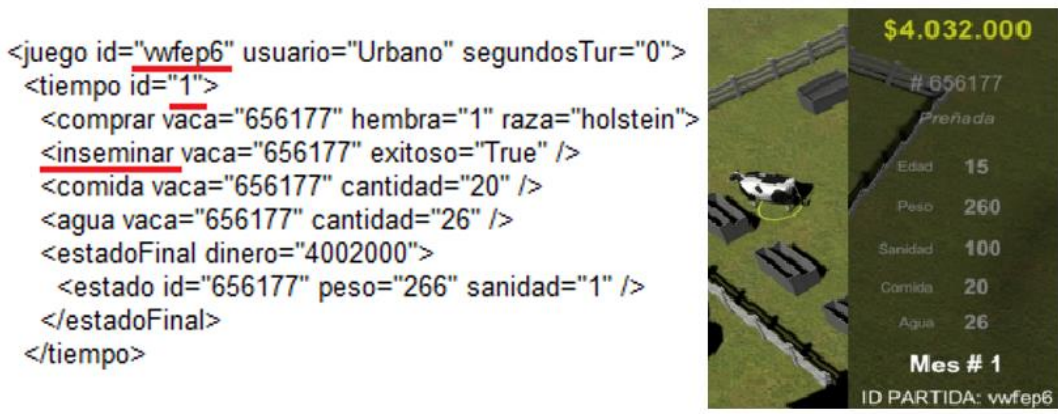

Fig. 9. Part of the XML file and Serious video game screen for a game in month 1

Figure10, presents the same game play through in the 22nd month. There were two animals, and the empty cow \# 783072 is selected. That cow was the offspring of cow \# 656177 and had just finished its lifting stage. In the left, a partial view of the XML file that logs the events of the month: the feeding and watering of cow \# 656177, the end of the lift of animal \#783072 (label "crecer"), the money and the animals' health status.

The XML must be transformed to migrate the data to the database. The transformation generates the database scripts in the following order:

1) Insert the parameters such as organization, farms, users, lots, third parties (the ID of the game is taken as the organization name, the farm, the user, and the lot)

2) Insert the animals of the game

3) Insert the money of the month

4) Insert every decision or event in the game

5) Update the state of every animal

6) Include the money of every month of the game 

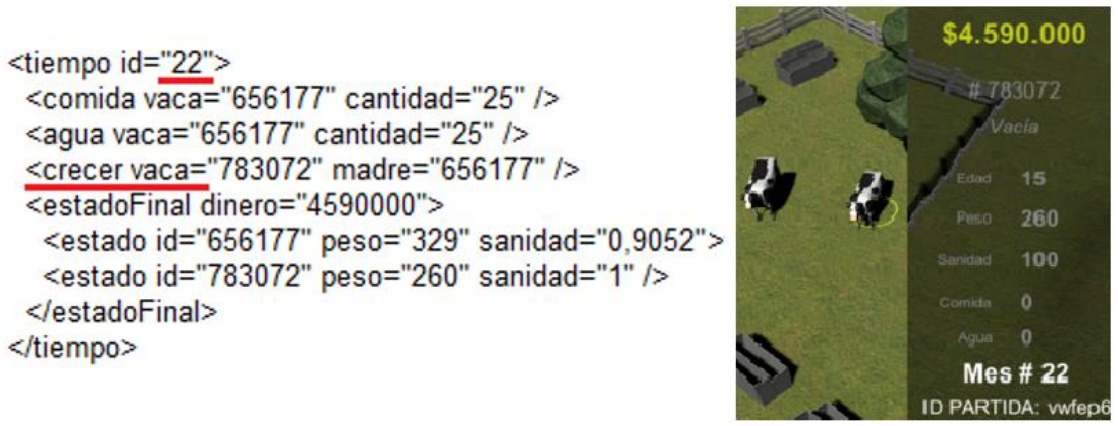

Fig. 10.Part of the XML File and Serious video game screen for a game in the month 22

Functionalities for management of real productive systems: During the training, the DSS allowed users to view information on the games that had been ruined in the Serious video game. After the training, it was used to manage the processes of the farm by making use of the same options and reports that the livestock farmer previously handled when reviewing results of his games in the Serious video game. The difference is that the farmer used the DSS with a real Bovine Production Systems. Additionally, some new or additional options are involved; some of these are:

1) Management of parameters and animals: Two features that the livestock farmer knows when checking results of their games in the Serious video game, this time as a report. When using them to manage a real farm, in addition to viewing them you must use them to record the data. The parameters correspond to the basic data for the operation of the farm, such as lots, third parties and races.

2) Events: They correspond to the registration of the options presented in Figure 12 , that is, it is the option to register and check the information that arises from the processes that occur in the farm such as Growth (Weight) *, Milking (Milk) *, Insemination (or Palpation) *, Births, Purchases, Sales, Transfers, Vaccination* and Deaths (* possible events to save from app, synchronously or asynchronously).

3) Forecast Management: It is an option that gives information on upcoming events, which are generated from the event log. For example, the proximity of birth or the need to Forecast Management: inseminate an animal, among others.

4) Genealogy: It is a report in which the data of the father, the mother and the date of birth are listed for each animal born on the farm.

Figure 11, presents User views of the DSS for mobile platforms, which are as follows:

a) Event Log: It is an option to record the events of the system.

b) Saved event: It is a report in which the data of the events in the mobile are listed.

c) Synchronization: This option shows the sending and fetching of data from server. 

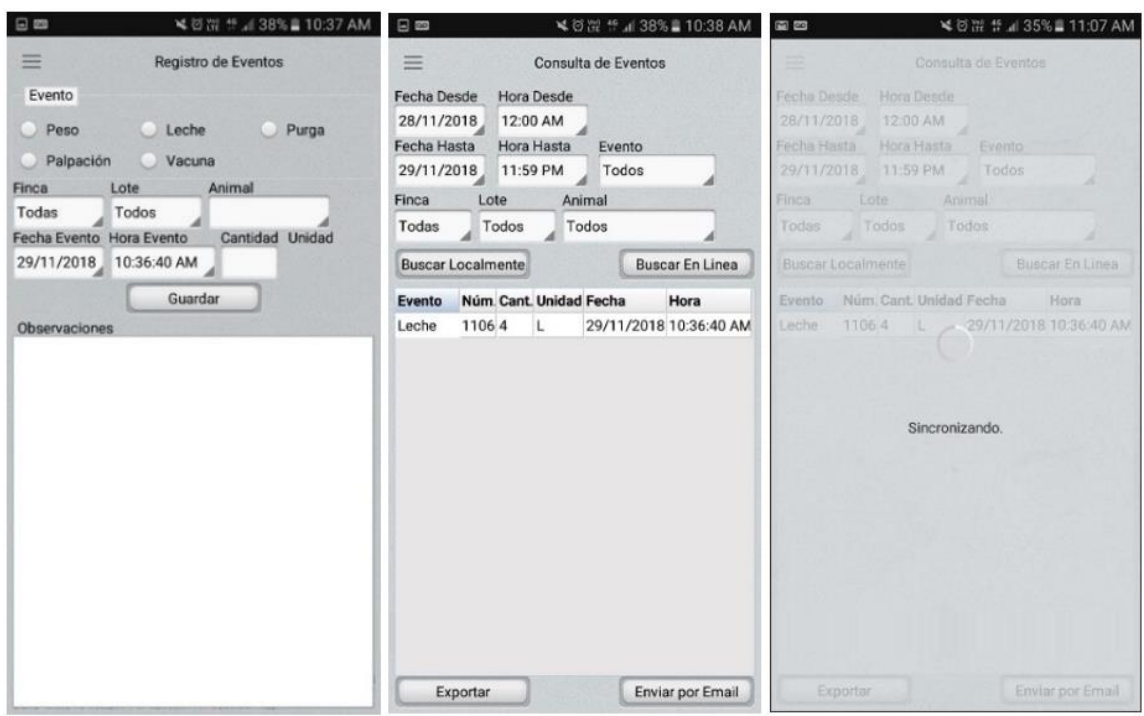

Fig. 11.User views of the DSS for mobile

Figure12, presents the "Events" in the Web version of the DSS. See that the option shows the date of the event, the date of registration and, if the event was synchronized, the date was saved on the mobile device.

\begin{tabular}{|c|c|c|c|c|c|c|c|c|}
\hline Peso & Lech€ & & Palpacion & Parto & Compra & Venta & \multicolumn{2}{|c|}{ Muerte } \\
\hline rcero & Movim. & $\#$ & $\begin{array}{l}\text { Fecha de } \\
\text { Evento }\end{array}$ & $\begin{array}{l}\text { Fecha de } \\
\text { Registro }\end{array}$ & $\begin{array}{l}\text { Fecha de } \\
\text { Sincroniz }\end{array}$ & Cant. & Precio & Sem \\
\hline $\begin{array}{c}\text { Omar } \\
\text { Lozano }\end{array}$ & רpra & 11 & $2020-03-29^{2}$ & $\begin{array}{c}2020-03-30 \\
08: 21: 48\end{array}$ & $\begin{array}{c}2020-03-30 \\
18: 47: 32\end{array}$ & 350 & 4000 & 174 \\
\hline
\end{tabular}

Fig. 12.Option to manage events in the Web Version of the DSS.

Productivity reports in the DSS: Some reports to check productivity are:

1) Demography Distribution: Presents a cake diagram with percentages according to animal demography on the farm.

2) Consolidated Production: Presents the total daily milk (total produced milk, litres) or weight production (total weight of animals, kilograms) for a range of dates

3) Production by Animal: Shows the behaviour curves of each animal according to their age, by event or for a range of dates. One of the reports is Production by Animal. Figure 13 shows the weight in kilograms of an animal, the DSS shows the gap between the registered weight and the ideal weight. 


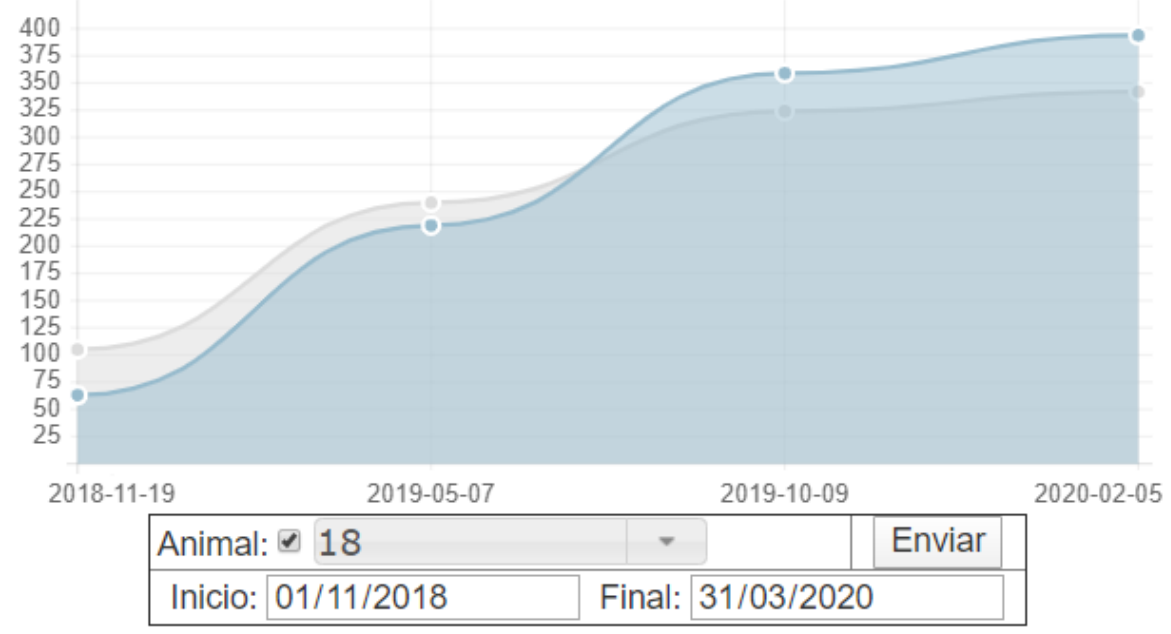

Fig. 13.Animal Production Report

Functionalities to measure the use of the video game and the DSS: The DSS also generates reports to measure how much the livestock farmers use the Serious video game and the DSS. Indicators can be viewed individually (by farmers) or by group (by the community). Reviewing the indicators in these reports allows for better monitoring of the appropriation strategy. The functionalities are made up of the following reports.

1) List of Games: The report shows the games played in the sessions to measure the performance of the livestock farmer. The list can be sorted by the total generated money to obtain a ranking of games in a specified period.

2) Participation Report: The Participation Report presents the dates on which livestock farmers have entered data of the real system. It's an indicator that measures the use of the DSS by community or livestock farmer. An example is presented in Figure 14.

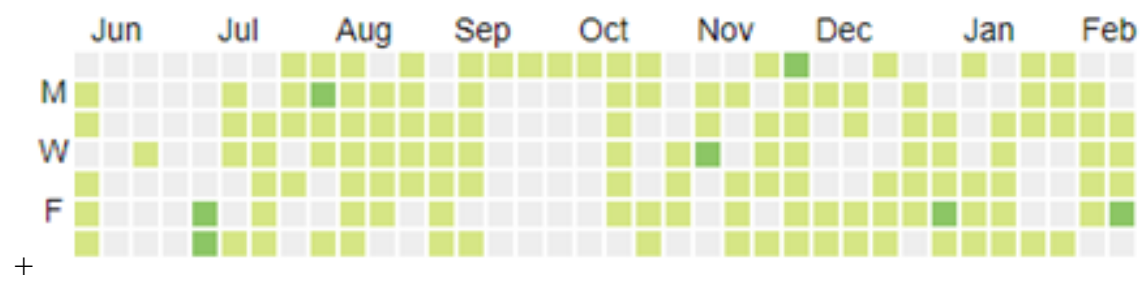

Fig. 14.Participation Report

Participation Indicators Report: The Participation Indicators Report presents, for each user, the number of registered animals and movements, and how many days were logged in the DSS. An example is presented in Figure 15, where it is observed that user 
\#1 logged 375 of the 709 days, he has been unaccompanied, which resulted in a $58 \%$ participation percentage.

\begin{tabular}{|c|c|c|c|c|c|c|c|c|c|}
\hline & $\%$ & IdOrg & Finca & Usuario & Animales & Movim & Ingresos & Posibles & Desde \\
\hline 1 & 58 & 26 & Llanadas & Eduardo & 28 & 1651 & 375 & 709 & $2018-06-25$ \\
\hline 2 & 53 & 30 & La Sierra & Omar & 14 & 1190 & 398 & 558 & $2018-11-23$ \\
\hline 3 & 60 & 35 & El Lago & Orlando & 14 & 1054 & 352 & 558 & $2018-11-23$ \\
\hline 4 & 58 & 40 & Manizales & Samuel & 16 & 1178 & 389 & 515 & $2019-01-05$ \\
\hline 5 & 47 & 42 & Florosa & Nelson & 16 & 1006 & 332 & 515 & $2019-01-05$ \\
\hline
\end{tabular}

Fig. 15.Appropriation Indicators Report

\section{Discussion}

The use of System Dynamics allows modelling the processes of a system in different scenarios that generate [25], systems that can be studied as dynamic systems, which can be explained and understood by making models that show the existing relationships that may exist between the variables that compose it and support the virtual experiment teaching with the model and simulate different situations [26], just the way it happens in this work, where the project was able to represent processes to the livestock farmers that they already understood but had not simulated and analyzed different alternatives on-farm management.

There are fundamental aspects in gamification such as the needs of the participants are determined, the possibility of proposing the content is given, there is motivation to learn and have fun provided by the game without losing the commitment to improve in the results [27] and to generate a sense of ownership and recognition of the participants as transformers in the way of carrying out the processes [9]. In this work, these aspects occur because the livestock farmers collaborate with the formulation of the model and the IT tools integrate, since that model supports the development of the mechanics of the video game and the generation of forecast reports in the DSS, which provides membership and recognition, and because the results of the games can be reviewed in the DSS, which provides a desire for improvement.

Games can help acquire data from learning processes and show how information can be managed in that system [28], two factors that are given in this work, where the users know the large volume of data required for the management of the farm and the successes and errors of his decisions each time they consult the DSS.

In this proposal, the requirement to determine the needs of the participants expressed by [29] was applied, and with this the knowledge acquisition, motivation and commitment of the livestock farmers were favored, in addition and as recommended of [30], an experience could be developed without the game serious to compare, in the strategy, the use achieved of the DSS.

Involving the use of IT tools for collaborative learning that allow their operation in different devices improves the understanding of the system [31], this work applies it since it is supported by tools developed specifically for small producers accompanied by training sessions that give the possibility of simulations carried on each farm. 
It is expected in a next version to integrate sensors in the DSS to facilitate the registration of processes such as milking and weighing and increase control in data acquisition as it happens in the DSS SCADA, which allows monitoring in agriculture [32].

\section{Conclusion}

The integration between the tools favoured the training since it eased the communication with the livestock farmers. The intention was to help them understand the use of the DSS in a process with incrementing coverage. That process started from the simulation model, continued with the simulation of the Bovine Production Systems and its administration in the Serious video game and ended with the search of the results in the DSS. These results are the product of the processes of migrating the data from the Serious video game. The goal of these advantages is to gain the trust of the livestock farmers in the DSS.

Considering that not many farms have internet access, the possibility of asynchronous communication provided by the mobile version is essential to carry out the appropriation process.

In this proposal, decisions such as insemination, weaning or animal growth (such as the one presented in figure 13), are alternatives in livestock production that are supported in a mathematical model, a fundamental feature in a DSS described in 2.1. With the finite-difference equations that were generated in the model, the expected behaviour is generated and presented along with the data recorded so that the farmer makes the comparison and proceeds to carry out the necessary actions. Furthermore, these equations were used in the mechanics of the video game.

Involving the livestock farmers in this gamification strategies and showing them the benefits presented by the tools and the validation through an iterative process of design and development, improving the understanding of the developer in regards to the complexity of the productive system and the necessity of information. This allows for a better design and increased the trust and interest of the livestock farmers in the strategy.

The System Dynamics contributed to a common language for the communication and understanding of the productive processes, due to the advantages it offers on the representation of the system and the visualization of the structure.

The serious video game and its ability to generate scenarios brought the livestock farmers closer to the IT. This allowed them to develop dexterity in the administration of the productive system and to improve the understanding of the processes their farms.

The DSS was strengthened by the Serious video game, as it provided users with the possibility of checking errors and successes made during the simulations. The expectation is that this will make the livestock farmers aware of the need to have an information system available for their real Bovine Production Systems. 


\section{$7 \quad$ References}

[1] Budiyanto, C. (2017). Decision Support Systems Development for an Artificial Insemination Project in Community based Precision Livestock Farming. IOP Conference Series: Materials Science and Engineering, London https://doi.org/10.1088/1757-899x/180/1/012242

[2] Federación Colombiana de Ganaderos (2015). Normativa General Agropecuaria. Retrieved from http://goo.gl/oBmyGp.

[3] Gómez, U, Orellana, M, Salinas, J. (2019). Appropriation of Information Technology Systems for Decision Making Support Systems by Agroindustry Producers Based on Simulation Models or Serious Games: A Review. Información tecnológica, 30(5), 331-340. https://dx. doi.org/10.4067/S0718-07642019000500331

[4] Sierra, J.(2017).Uso TIC agrícola aún tiene ajustes en la cosecha. Retrieved from http://goo.gl/BpwrrL.

[5] Walmsley, B., \& Oddy, V. (2018). Modelling systems to describe maternal productivity with the aim of improving beef production efficiency by eliciting practice change. Animal production science, 58(1), 193-205. https://doi.org/10.1071/an14874

[6] Whittenbury, K., \& Davidson, P. (2009). Beyond adoption: The need for a broad understanding of factors that influence irrigators' decision-making. Rural Society, 19(1), 4-16, https://doi.org/10.5172/rsj.351.19.1.4

[7] Molano, A. (2016). Tecnología para la agroindustria y las ciudades inteligentes en Colombia. (Colombia Digital) Retrieved from http://goo.gl/j81vbY

[8] Filip, F. (2012). A decision-making perspective for designing and building information systems International. Journal of Computers Communications \& Control, 7(2), 264-272, https:// doi.org/10.15837/ijccc.2012.2.1408

[9] Lundström, C., \& Lindblom, J. (2018). Considering farmers' situated knowledge of using agricultural decision support systems (AgriDSS) to Foster farming practices: The case of CropSAT. Agricultural Systems, 159, 9-20, https://doi.org/10.1016/j.agsy. 2017.10.004

[10] Pressman, R. (2014). Ingeniería del Software. México: Mc Graw Hill.

[11] Sarinho, V. (2019). Masters of the process: a board game proposal for teaching software management and software development process. XXXIII Brazilian Symposium on Software Engineering, 532-536. Sao Paulo. https://doi.org/10.1145/3350768.3352459

[12] Tarifa, E., Martínez, S., \& Chalabe, S. (2013). Desarrollo de Sistemas de apoyo para la toma de decisiones en procesos productivos. XV Workshop de investigadores en ciencias de la computación, Entre ríos. https://doi.org/10.17488/rmib.38.1.12

[13] Rosso, C., Lauric, A., De Leo, G., Bilotto, F., Carbonell, C., \& Machado, C. (2018). Modelación productiva, económica y emisión de metano en sistemas de cría vacuna de Bahía Blanca y Coronel Rosales. Revista de investigaciones agropecuarias, 44(2), 129-135. https://doi.org/10.4067/s0719-38902019005000102

[14] Daza, L., Hernández, C., Quijano, A., \& Serna, J. (2017). Plan estratégico del Departamento de Santander. Retrieved from goo.gl/4fSpDW

[15] Gómez U., Andrade H., Vásquez C. (2015). Lineamientos Metodológicos para construir Ambientes de Aprendizaje en Sistemas Productivos Agropecuarios soportados en Dinámica de Sistemas; Información Tecnológica, 25(4), 125-136, https://doi.org/10.4067/ s0718-07642015000400016

[16] Hsu, C., Tsai, M., Chang, Y., \& Liang, J. (2017). Surveying in-service teachers' beliefs about game-based learning and perceptions of technological pedagogical and content knowledge of games. Journal of Educational Technology \& Society, 20(1), 134-143.

[17] Schell, J. (2014). The Art of Game Design: A Book of Lenses. Boca Ratón: CRC Press. 
[18] Victoria, R., Utrilla, S., \& Santamaría, A. (2017). Aprendizaje basado en juegos. Una alternativa viable para la enseñanza significativa de la sustentabilidad. Revista Electrónica sobre educación media y superior, 4(7). https://doi.org/10.14201/gredos.129403

[19] Richey, R., \& Klein, D. (2014). Design and development research. New York: Handbook of research on educational communications and technology.

[20] Salinas, J., Negre, F., Gallardo, T., \& Escandell, C. (2006). Modelos didácticos en entornos virtuales de formación: identificación y valoración de elementos y relaciones en los diferentes niveles de gestión. Congreso internacional EDUTEC. Tarragona (España).

[21] Merriam, S. (2009). Qualitative research. A guide to design and implementation. San Francisco: Jossey-Bass.

[22] Andrade, H., Dyner, I., Espinosa, A., López, H., \& Sotaquirá, R. (2001). Pensamiento Sistémico, Diversidad en búsqueda de unidad. Bucaramanga: UIS.

[23] Kanti, B., Arshad, B., Mohamed, F., \& Noh, K. (2018). System dynamics: modelling and simulation. Singapor: Springer verlag.

[24] Unity. (2018). Unity. Retrieved from https://www.unitynetwork.com.

[25] Featherston, C., \& Doolan, M. (2013). Using System dynamics to inform scenario planning: a case study. The 31 st international conference of the System Dynamics Societ. Cambridge.

[26] Wu, J. (2018). A Space Design Teaching Model Using Virtual Simulation Technology. International Journal of Emerging Technologies in Learning, 13(6), 163-175, https://doi.org/ 10.3991/ijet.v13i06.8585

[27] Papadakis, S. (2020). Evaluating a game-development approach to teach introductory programming concepts in secondary education. International Journal of Technology Enhanced Learning, 12 (2), 127-145, https://doi.org/10.1504/ijtel.2020.106282

[28] Vidakis, N., Barianos, A., Trampas, A., Papadakis, S., Kalogiannakis, M., \& Vassilakis, K. (2019). Generating Education in-Game Data: The Case of an Ancient Theatre Serious Game. 11th International Conference on Computer Supported Education. Crete. https://doi.org/10 $.5220 / 0007810800360043$

[29] Papadakis, S., \& Kalogiannakis, M. (2017). Using gamification for supporting an introductory programming course. the case of classcraft in a secondary education classroom. Interactivity, Game Creation, Design, Learning, and Innovation, 366-375, Springer, Cham. https://doi.org/10.1007/978-3-319-76908-0_35

[30] Papadakis, St., Trampas, A.-M., Barianos, A.-K., Kalogiannakis, M., \& Vidakis, N. (2020). Evaluating the Learning Process: The "ThimelEdu" Educational Game Case Study. Proceedings of the 12th International Conference on Computer Supported Education, 2, 290-298, https://doi.org/10.5220/0009379902900298

[31] Heflin, H., Shewmaker, J., \& Nguyen, J. (2017). Impact of mobile technology on student attitudes, engagement, and learning. Computers \& Education, 107, 91-99, https://doi.org/10 $.1016 /$ j.compedu.2017.01.006

[32] Padilla, J., \& Caicedo, J. (2017). Agro-SCADA: An SCADA system to support Sensor Monitoring in Agriculture. International Conference on Agro BigData and Decision Support Systems in Agriculture, Montevideo.

\section{Authors}

Urbano Eliécer Gómez Prada is a PhD student in Educational technology at University of the Balearic Islands, Spain. Professor in the Engineering School at the Bolivarian Pontifical University. ORCiD: https://orcid.org/0000-0001-6780-6648. Email: urbano.gomez@upb.edu.co 
Martha Lucía Orellana Hernández is PhD in educational technology by the University of the Balearic Islands (UIB), Spain. Professor at the Autonomous University of Bucaramanga (UNAB), Colombia. ORCiD: https://orcid.org/0000-0002-1468-7857.

Jesús María Salinas Ibáñez is $\mathrm{PhD}$ in Educational technology by the University of the Balearic Islands (UIB), Spain, Director of the Institute of Educational Research and Innovation (IRIE). ORCiD: http://orcid.org/0000-0002-3043-8455

Article submitted 2020-04-03. Resubmitted 2020-06-03. Final acceptance 2020-06-04. Final version published as submitted by the authors. 